\title{
Investigation of Customer Knowledge Management (CKM) Dimensions: A Survey Research
}

\author{
Prof. Dr. Ali Sanayei (Corresponding author) \\ ITM Research Group, University of Isfahan \\ Isfahan 81746-7341, Iran \\ Tel: 98-913-115-4945Ｅ-mail: Info@DrSanayei.com \\ Majid Sadidi \\ Department of Management, University of Shaikhbahaee \\ Behesht Street, Baharestan Town, Isfahan, Iran \\ Tel: 98-913-207-9523 E-mail: majid_sadidi@yahoo.com \\ Accepted: June 16, 2011 \\ Published: November 1, 2011 \\ URL: http://dx.doi.org/10.5539/ijbm.v6n11p234
}

Received: May 1, 2011

doi:10.5539/ijbm.v6n11p234

\begin{abstract}
Nowadays, regarding its widespread and extensive competition, polymeric fittings and pipe industry is in need of using applicable systems in identifying, attracting, and retaining customers. Therefore, Customer Knowledge Management (CKM) system, which aims at promoting and perfecting the quality of customer-organization inter-relation, can be of great help and assistance to those organizations dealing with this type of industry. Consequently, the aim of the present article is to investigate and assess the four dimensions of CKM in polymeric pipe \& fitting manufacturers in one of the strongest and most active centers, Isfahan province. The results reveal that the organizations dealing with this type of industry are demonstrating a very weak and feeble connection among the four dimensions of Content, Competence, Collaboration, and Composition of CKM.
\end{abstract}

Keywords: Knowledge management, Customer relationship management, Customer knowledge management

\section{Introduction}

Competition in today's market has been transmitted from hardware domain to that of software, and recently to that of information and policies. It is straightforward that organizations will progress and thrive only if they think up methods and processes to meet their needs comparatively better. In this regard, knowledge management and customer relationship management have been the focus of attention in organizations and academic contexts since both to obtain the constant benefits of competition through the optimization of the organizational resources in order to support commerce (Gebert, et al., 2003). Customer relationship management in competitive markets has inspired the organizations to look into ways to be in touch with a widespread scope of customers, and also approaches to gain its knowledge. It could be ventured to say that it would impossible to keep in touch with a wide scope of customers without employing knowledge management (Sparks, 2005). To enhance the efficacy, influence and the trustworthiness of desirable goods and services to customers, and to meet their satisfaction, the organization ought to manage its knowledge about customers. Consequently, it seems that knowledge management can be gainful to execute better customer relationship management. For this reason, the present article attempts to investigate upon the impact of knowledge management on successful customer relationship management. Also, the article will, in the end, present the integrated model of the both notions. Prior to the analysis of the presented consistent model, elaborated definitions will clarify the point better.

\section{Customer Relationship Management}

Customer relationship management is a process to identify, select, acquire, develop and retain profitable customers (Payne \& Frow, 2004). Having long-term relationships with each one of the customers, CRM both considers their requests and requirements and tries to come up with their satisfaction. Customer relationship management is not quite a new notion, but it has employed the most developed technology namely (IT) in order to serve the customers in practice (Schmid, 2001). CRM is recognized as one-to-one marketing in business (Peppers \& Rodgers, 1999), which in turn means organizations are to utilize CRM to replace the wholesale perspective with maintaining customers through appropriate relationship with each one of them (Peppers \& Rodgers, 1993). Therefore, CRM is a modern tool to analyze customers' information that acquires its data from various sources such as internet, stores, interaction centers, exhibits, etc (Fickel, 1999). Providing that customer relationship management system be devised and implemented so well, it could be stated that thorough identification of the customers will be achieved. More often than not, CRM strategy is based on four main objectives: 
- to hearten the other companies' customers as well as the potential customers to embark on the first purchase

- to encourage the first-time customers for further purchase

- keeping the temporary customers as permanent customers

- providing decent services for faithful customers

Customer relationship management enables the managers to employ their customers' data to increase their production, provide better services, and boost their long-term profit.

\section{Knowledge Management}

Nowadays, having knowledge and utilizing it in organizations has become a procedure which can lead them to the advantage of competition. Availability of knowledge in organizations is such a valuable fund that empowers them in various complicated situations (Davenport \& Marchand, 2001). Knowledge management includes supporting innovations, brainstormed ideas and utilization of organizational thinking power. It also embodies acquiring appropriate insight and experience to make the data accessible and useful for the time and place where they come in handy, and also for those who need it (Parlby \& Taylor, 2000). Knowledge management is an approach which creates data to meet the managers', customers' and operators' satisfaction. In other words, knowledge management is an inclusive process that considers identification, transmission and usage of accurate data and experience in organizations. The main principles of knowledge management include implementation and maintenance of the organizational and technical infrastructures as the indispensible groundwork to spread knowledge and to opt for specific technologies. All available sources of information such as personnel, information centers, documents and files are gathered and classified in right categories. All the data will be accessible in many ways everywhere. The appropriate data will be provided for right stuff and systems at right time (Davenport \& Marchand, 2001). Knowledge can be divided into two groups: implicit and explicit. Explicit knowledge is subjective, reasoned and logical. In other words, explicit knowledge is a collection of policies, approaches, soft wares, documents, instructions, reports and objectives in each organization. Explicit knowledge can be stated as words and numbers, or given in forms of data, scientific formulae, detail descriptions and instruction manuals. This knowledge can be simply distributed among people both officially and systematically (Nonaka \& Takeuchi, 1995). The other type of knowledge is implicit that is totally personal and can rarely be distributed in specific forms among people. Mental insight, intuition and hunches account for this type of knowledge. Implicit knowledge has deep roots in experimental activities, objectives, values and feelings (Nonaka \& Takeuchi, 1995). Organizations must enjoy both explicit and implicit knowledge in management in order to manage their data. That is why they are after preparing good cycles of available knowledge.

Information cycle or so-called knowledge management includes four sections: first, accessible knowledge inside the organization must be identified, collected and stored in a proper place. Next, information should be shared with others to add to the data and regenerate information. This way, the acquired knowledge can be utilized to attain the aspired objectives (Davenport \& Marchand, 2001).The presented introduction about knowledge management can generally be applied to many organizations. However, what is highlighted in this article is knowledge management process in commercial circumstances which is further elaborated below.

\section{Deriving an integrated customer KM process model}

\subsection{CRM process model}

Marketing, sales, and service are primary business functions (Porter and Millar, 1985) with the characteristics of a high degree of direct customer interaction and knowledge intensity. Based on the three primary processes identified by Porter (1998), and the definition of sub-processes and tasks common in CRM literature (Kotler, 2003; Peppers and Rogers, 1993; Unruh, 1996) Were identified campaign management, lead management, offer management, contract management, complaint management, and service management as the six relevant CRM business processes (Figure 1).

Campaign management is the core marketing process which fulfills the idea of interactive, individualized contacts in contrast to traditional transaction marketing (Gro"nroos, 1994). It deals with the planning, realization, control and monitoring of marketing activities towards known recipients. Marketing campaigns are individualized (one-to-one marketing) (Peppers and Rogers, 1993) or segment specific and offer communication channels for feedback. The objective of campaign management is to generate valuable opportunities or "leads" as the basis for lead management. Lead management is the consolidation, qualification, and prioritization of contacts with prospective customers. The objective is to provide sales staff with a qualified and prioritized list of presumably valuable prospects to be precisely addressed within the offer management process. Offer management is the core sales process. Its objective is the corporation-wide consistent creation and delivery of individualized, binding offers. An offer management process may be triggered by a customer inquiry, a qualified lead, or a discovered opportunity. Contract management is the creation and maintenance of contracts for the supply of products and services. As such, it supports offer management or service management processes. Contract management also comprises the maintenance and adjustment of long-term contracts, e.g. for outsourcing agreements or insurances.

Service management is the planning, realization and control of measures for the provision of services. A service is an intangible output of an enterprise generated with direct involvement of customers. Examples include 
maintenance, repair, and support activities in the after-sales phase as well as the provision of financial or telecommunication services after the conclusion of contracts. Within the scope of complaint management, articulated dissatisfaction of customers is received, processed, and communicated into the enterprise (Gro"nroos, 2000). The objectives are to improve customer satisfaction in the short-run by directly addressing problems that led to complaints and to design a continuous improvement process in the long-run.

Operative CRM system components directly support the six CRM sub-processes described above. Analytical components primarily emphasize on the processes campaign management, lead management, and offer management by evaluating different data sources and deriving conclusions about what customers are likely to need and buy. To cover the collaborative aspects on the process level, CRM requires activities to design interfaces to customers at customer interaction points. Interaction management is the design and selection of media-based communication channels like interactive voice response (IVR) or the world wide web (WWW) to achieve an optimal channel mix (Senger et al., 2002). The objective is to increase the quality and value of interactions while at the same time decreasing the cost of interactions by shifting customers to less costly channels, e.g. web self-service. Closely connected to interaction management is channel management which addresses the challenge of configuration and synchronization of different communication channels (Coughlan et al., 2001). Key objectives are to define organizational responsibilities for each channel, to avoid conflicts between channels, and to ensure consistent knowledge flows across different channels.

4.2 Integrating customer relationship management and knowledge management

To achieve their goal of providing a solution for the process of the customers, enterprises need to focus on three sorts of knowledge in CRM processes ( $\mathrm{O}^{*}$ sterle, 2001). They make up what we consider to be customer knowledge.

- They need to understand the requirements of customers in order to address them. This is referred to as "knowledge about customers".

- The information needs of the customers in their interaction with the enterprise require "knowledge for customers".

- Finally, customers possess knowledge about the products and services they use as well as about how they perceive the offerings they purchased. This "knowledge from customers" is valuable as it feeds into measures to improve products and services. Efforts need to be made to channel this knowledge back into the enterprise.

To comprehensively cover the CKM approach, the model would also have to encompass the layers of strategy and information systems (Alice, et al., 2008). These layers have been omited in the graphical representation to avoid excessive complexity but we will explain them in this section. On a strategy level, companies need to determine how CKM can support business goals and processes and use these as guidelines for designing the CKM processes and performance indicators (Jyhjong Lin, 2007). The process level, our main focus in this paper, is derived as follows: like the SECI model of Nonaka/Takeuchi (Nonaka and Konno, 1998), the CKM process model is based on the fact that there are two types of knowledge, implicit (or tacit) and explicit. According to Polanyi (1966), who introduced the concept of tacit knowledge, each individual possesses an amount of implicit knowledge which influences the ability to articulate and therefore explicate and create knowledge. Implicit knowledge includes past experiences and influences the perception of the environment. However, explicit and implicit knowledge as such are not separable from the particular individual possessing it. Therefore, we term it the knowledge aspect "competence". As a consequence, the organization can only directly manage explicated knowledge in the form of media such as text or images which we term the knowledge aspect "content". Content is part of the business processes and exists independently of individuals. Similar to the revised SECI model of Hedlund and Nonaka (1993), the CKM process model also introduces two aspects that take into account how knowledge is created, disseminated and used within an organization. As a consequence, the model contains elements of both the epistemological view and the ontological view with an agent dimension. The ontological view is represented by the two aspects of "collaboration" and "composition". Collaboration deals with the creation and dissemination of knowledge among few individuals, e.g. in project teams. The knowledge aspect composition, on the other hand, deals with the dissemination and usage of knowledge among a large number of individuals. An important issue for composition is helping people find explicated knowledge, for example, in enterprise portals. The four knowledge aspects deliver services that support the CRM sub-processes. That sometimes requires support processes such as managing content or competency information from creation to application in a lifecycle. The aspects of collaboration and composition provide an infrastructure that supports the provision of knowledge to business processes while not being a process itself. Nevertheless, as proposed by the business engineering approach all knowledge aspects need to be supported by information systems that deliver specific functions for each aspect. The aspect content typically requires the use of content management or document management systems. The aspect competence makes use of expertise directories as well as skill management or e-learning systems. E-mail, group information tools, and instant messaging systems are typical functions that support the aspect of collaboration. Finally, the aspect of composition, which primarily deals with search and navigation, uses systems such as knowledge mining systems, personalization, taxonomy management systems, and knowledge maps. 


\section{Research Methodology}

The basic research methodology in this article, to examine and assess the relation among the four dimensions of CKM, namely: Content, Competence, Collaboration, and Composition, was to use a survey. To this end, twenty-two manufacturer in Isfahan (the information of which was drawn from the Department of Industry and Economic Affairs) were chosen as the sample of the current study. For the data collection procedure of the study, the researcher chose the use of a questionnaire. Through the administration of this questionnaire, containing twenty-nine multiple-choice questions (each having five answer choices) based on the Likret Scale, it was attempted to realize Sales Managers' and Marketing Managers' opinions of these manufacturers over the four dimensions of CKM. The 29 item had reliability (Cronbach's $\alpha$ ) of 0.924 . A number of questions regarding the customer satisfaction/complaint recording system used in the company, the customer data collection method employed and the technology used to analyze customer data were also part of the questionnaire.

The questionnaires were handed out to the participants of the study either through a direct encounter or through an e-mail. Out of seventy handed-out questionnaires, fifty-three were returned to the researcher with a response rate of seventy-six percent (76\%). Following, the results of the survey are presented.

\section{Data analysis and discussion}

The age of the majority of the respondents was between 35-44 years, 24.8 percent of them were female. Table 1 depicts the frequencies concerning the use of customer-oriented KM instruments in polymeric pipe \& fitting manufactures in Isfahan province .Overall, the findings show that less than half of the organizations always, or frequently use, instruments to evaluate external environment and to assess and obtain knowledge from customers. However, only about one-quarter of them systematically carry out market research. It is also worth mentioning that 44 percent of the respondents carry out customer satisfaction research.

Table 2 depicts the percentages of the organizations that use any type of a customer satisfaction and complaint recording system; 43 percent of them use questionnaires, e-mails, call centers and periodic market research and customer surveys in order to collect customer satisfaction data; 64 percent of them collect customer complaint data. It is concluded, therefore, that about half the organizations do not usually employ any customer KM methods and have not adopted any CRM philosophy.

Table 3 depicts the type of the system used to collect the data and Table 4 the technology employed to analyze these data and transform them into meaningful information.

Table 5 depicts the participants' opinion analysis regarding the dimensions of CKM. As it is obvious from the table, polymeric fittings and pipe manufacturing companies in Isfahan have a very shallow and little understanding of the CKM dimensions. This is to say that the flow of written knowledge and its distribution among the workers of the companies is very weak. Nevertheless, the Competence aspect of CKM seems to in a better condition in comparison to other three dimensions.

\section{Conclusion}

Active manufacturers in polymeric fittings and pipe industry, regarding the high level of competition that exists in their working environment, should be seeking the application of systematic, methodical, and scientific interventions to maintain a proper and firm long-term relation with their customers. One of the means for getting to this end is the use of Customer Knowledge Management (CKM) system. Therefore, the main goal of the present study was first to determine and then to assess different dimensions of CKM in polymeric fittings and pipe manufacturing companies. Studies reveal that many of the manufacturing companies don't rely on a systematic use of Customer Evaluation, Marketing Researchs, Customer Satisfaction Measurements, and Market Assessment techniques. Applying these techniques and methods can be a helpful device in identifying potential customers, identifying the market environment and market competitors, and thereupon, be considered as a useful source for nourishing the CKM. Moreover, it seems that more than half of the manufacturing companies lack an efficient method of measuring customers' satisfaction and complaints. A systematic method of gathering and recording this information can be very obliging and useful in the creation and distribution of information in CKM. On the other hand, many of the manufacturing companies don't enjoy a well-suited technology in the process of data analysis. Many of them currently use MS Excel or Access as their main data analysis programs, and so few of them are familiar with using other foreign resources. Eventually, reviewing customer knowledge dimensions in these companies reveal that none of them has an appropriate and adequate understanding of the four dimensions of CKM, disclosing the fact that the process of recording information in forms and documents along with the distribution of information among the companies' employers is at its lowest stage.

\section{References}

Alice H.W. Yeung, Victor H.Y. Lo, Andy C.L. Yeung, T.C., \& Edwin Cheng. (2008). Specific customer knowledge and operational performance in apparel manufacturing. International Journal of Production Economics, 114, pp 520-523. http://dx.doi.org/10.1016/j.ijpe.2007.06.011

Coughlan, A., Anderson, E., Stern, L.W., and El Ansary, A. (2001). Marketing Channels. Prentice-Hall, New Jersey, NJ.

Davenport, T.H and Marchand, D. (2001). Is KM just good information management? Financial Time Limited, No. $04 / 25, \mathrm{p} 2$.

Fickel , L. (1999). Kown your customer. CIO Magazine, Vol. 12 No. 21 , pp. 62-72 
Gebert henning, Geib Malte, Kolbe lutz and Brenner. (2003). Knowledge-enabled customer relationship management :integrating customer relationship management and knowledge management concepts,journal of knowledge management, Vol 7, No 5,pp107-123

Gro"nroos, C. (1994). From marketing mix to relationship marketing: towards a paradigm shift in marketing. Management Decision, Vol. 32 No. 2, pp4-20. http://dx.doi.org/10.1108/00251749410054774

Grönroos, C. (2000). Service Management and Marketing: A Customer Relationship Management Approach. Wiley, Chichester.

Hedlund, G., and Nonaka, I. (1993). "Models of knowledge management in the west and Japan", in Lorange, B., Chakravarthy, B., Roos, J. and Van de Ven, H. (Eds), Implementing Strategic Processes, Change, Learning and Cooperation, Macmillan, London,pp117-144

Jyhjong Lin. (2007). An object-oriented development method for Customer Knowledge Management Information Systems. Knowledge-Based Systems, Volume 20, Issue 1, pages 17-36. http://dx.doi.org/10.1016/j.knosys.2006.07.003

Kotler, P. (2003). Marketing Management. Prentice-Hall, Englewood Cliffs, NJ.

Nonaka, I, and H. Takeuchi. (1995). The Knowledge - Creating company: How Japanese companies create the dynamics of innovation. New York: Oxford University Press.

Nonaka, I., and Konno, N. (1998). The concept of 'Ba': building a foundation for knowledge creation. California Management Review, Vol. 40 No. 3, pp 40-54

O "sterle, H. (2001). "Enterprise in the information age", inO " sterle, H., Fleisch, E. and Alt, R. (Eds), Business Networking: Shaping Collaboration Between Enterprises, Springer, Berlin, pp 17-54

Parlby, D., \& Taylor, R. (2000). The power of knowledge: A business guide to knowledge management. [Online] Available: www. Kpmgconsulting.com

Payne Adrian, \& Frow pennie. (2004). The role of multichannel integration in customer relationship management. Industrial Marketing Management, Volume 33, Issue 6, PP 527-538.

Peppers , D., and Rogers, M. (1999). The One to One Manager: Real-World Lessons in Customer Relationship Management. Doubleday, New York, NY.

Peppers, D., and Rogers, M. (1993). The One to One Future - Building Relationship One Customer at One Time. Currency Doubleday, New York, NY.

Polanyi, M. (1966). The Tacit Dimension. Routledge \& Kegan Paul, Gloucester.

Porter, M.E. (1998). Competitive Advantage: Creating and Sustaining Superior Performance. Free Press, New York, NY.

Porter, M.E., and Millar, V.E. (1985). How information gives you competitive advantage. Harvard Business Review, Vol. 63 No. 4, pp 149-160

Schmid, R.E. (2001). An Architecture for customer relationship management Dissertation. Thesis University of St Gallen, St Gallen.

Senger, E., Gronover, S., and Riempp, G. (2002). "Customer web interaction", in Ramsower, R., Windsor, J. and DeGross, J. (Eds), Proceedings of the Eighth Americas Conference on Information Systems, Association for Information Systems, Dallas, TX, pp. 1966-76.

Sparks, G. (2005). The business process model. [Online] Available: http//:www.sparxsystems.com.au/WhitePapers/ The_Class_Model.pdf [April2005]

Unruh, J.A. (1996). Customers Mean Business: Six Steps to Building Relationships that Last. Perseus Publishing, Reading, MA.

Table 1. Customer oriented instruments

\begin{tabular}{|l|c|c|}
\hline & Never/sometimes(\%) & Frequently/always(\%) \\
\hline Assess customers & 52 & 48 \\
\hline Carry out customer satisfaction research & 56 & 44 \\
\hline Carry out market research & 75 & 25 \\
\hline Obtain knowledge from customers & 59 & 41 \\
\hline Evaluation of external environment and markets & 54 & 46 \\
\hline
\end{tabular}

Table 2. Customer satisfaction/ complaining recording system

\begin{tabular}{|l|c|c|}
\hline \multirow{2}{*}{} & \multicolumn{2}{|c|}{ Percent } \\
\cline { 2 - 3 } & Yes & No \\
\hline Customer satisfaction recording system & 43 & 57 \\
\hline Customer complaining recording system & 64 & 36 \\
\hline
\end{tabular}


Table 3. Customer data collection method

\begin{tabular}{|l|c|c|}
\hline \multirow{2}{*}{} & \multicolumn{2}{|c|}{ Percent } \\
\cline { 2 - 3 } & Internet & Non-Web-based market research \\
\hline Customer satisfaction data collecting system & 20 & 80 \\
\hline Customer complaining data collecting system & 32 & 68 \\
\hline
\end{tabular}

Table 4. Technology used to analyse customer data

\begin{tabular}{|l|c|c|c|}
\hline & \multicolumn{3}{|c|}{ Percent } \\
\cline { 2 - 4 } & Excell-Access & Statistical package & Outsourced to third party \\
\hline Customer satisfaction recording system & 78 & 18 & 4 \\
\hline Customer complaining recording system & 82 & 16 & 2 \\
\hline
\end{tabular}

Table 5. CKM aspects situation

\begin{tabular}{|l|c|c|c|c|}
\hline & Minimum & Maximum & Mean & Std. \\
\hline Content & 1.60 & 3.80 & 2.94 & .502 \\
\hline Competence & 1.80 & 3.80 & 2.97 & .580 \\
\hline Collaboration & 1.60 & 4.60 & 2.89 & .796 \\
\hline Composition & 2.00 & 3.80 & 2.78 & .606 \\
\hline Content & 1.60 & 3.80 & 2.94 & .502 \\
\hline
\end{tabular}
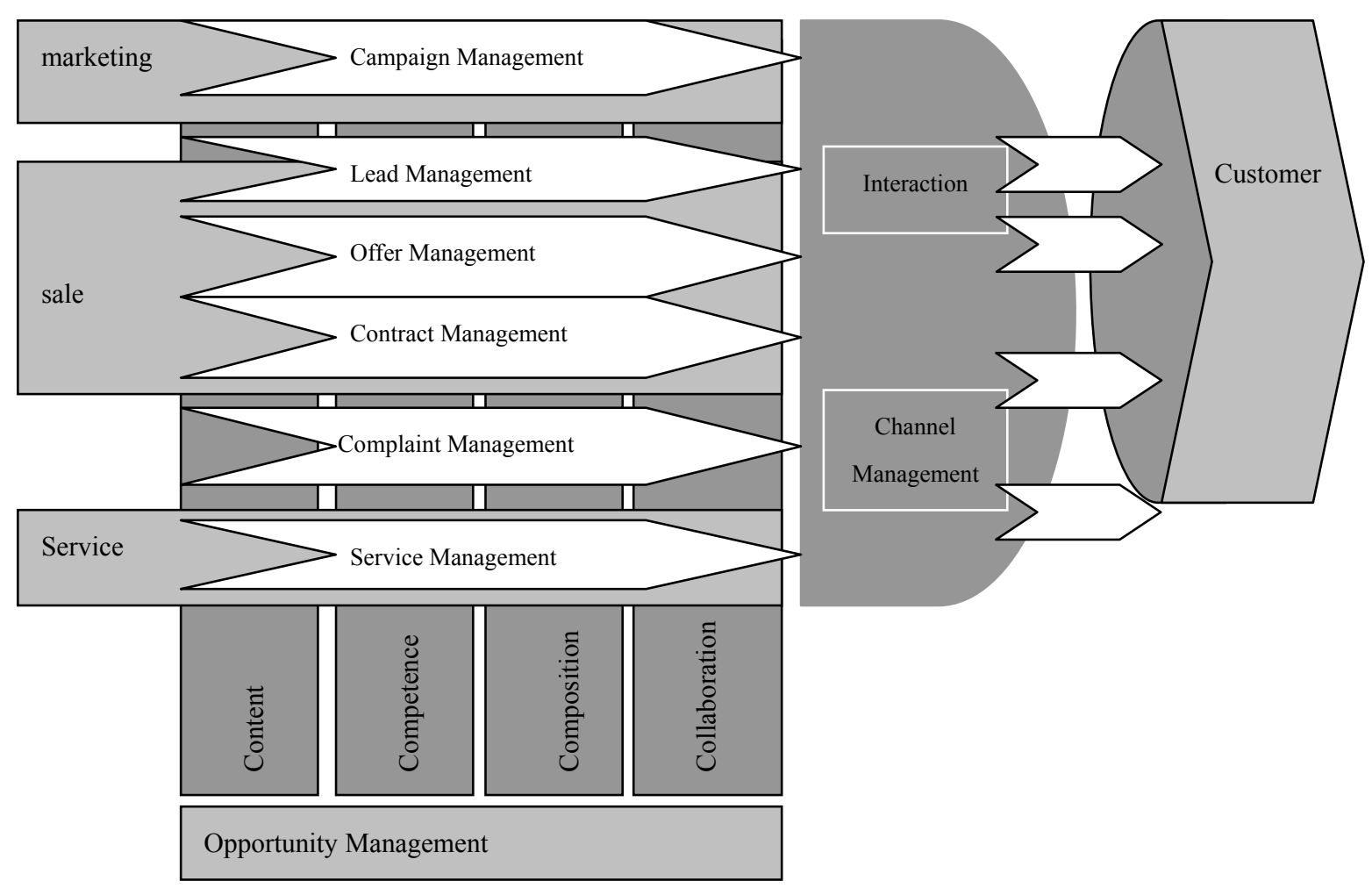

Opportunity Management

Figure 1. CKM model (Gebert, et al., 2003) 